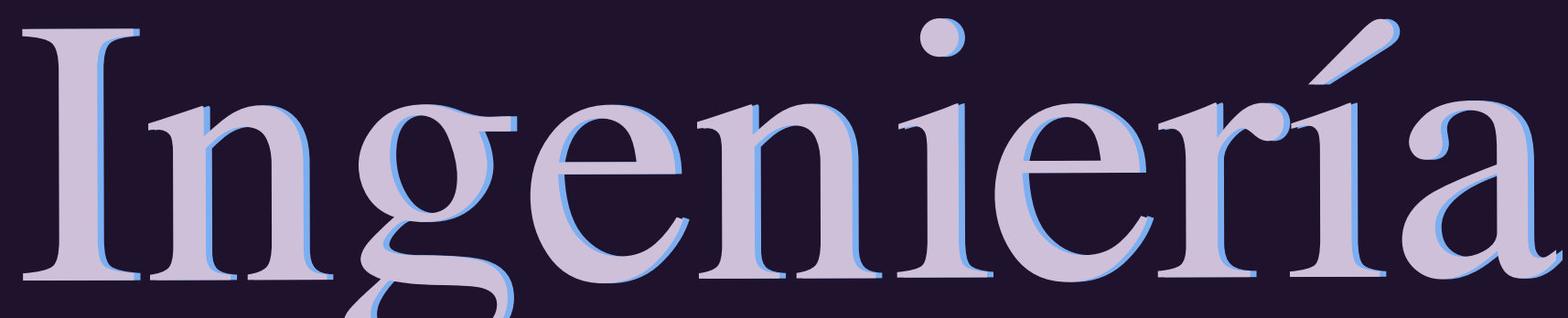

Revista de la Universidad de Costa Rica

ENERO / JUNIO 2020 - VOLUMEN 30 (1)
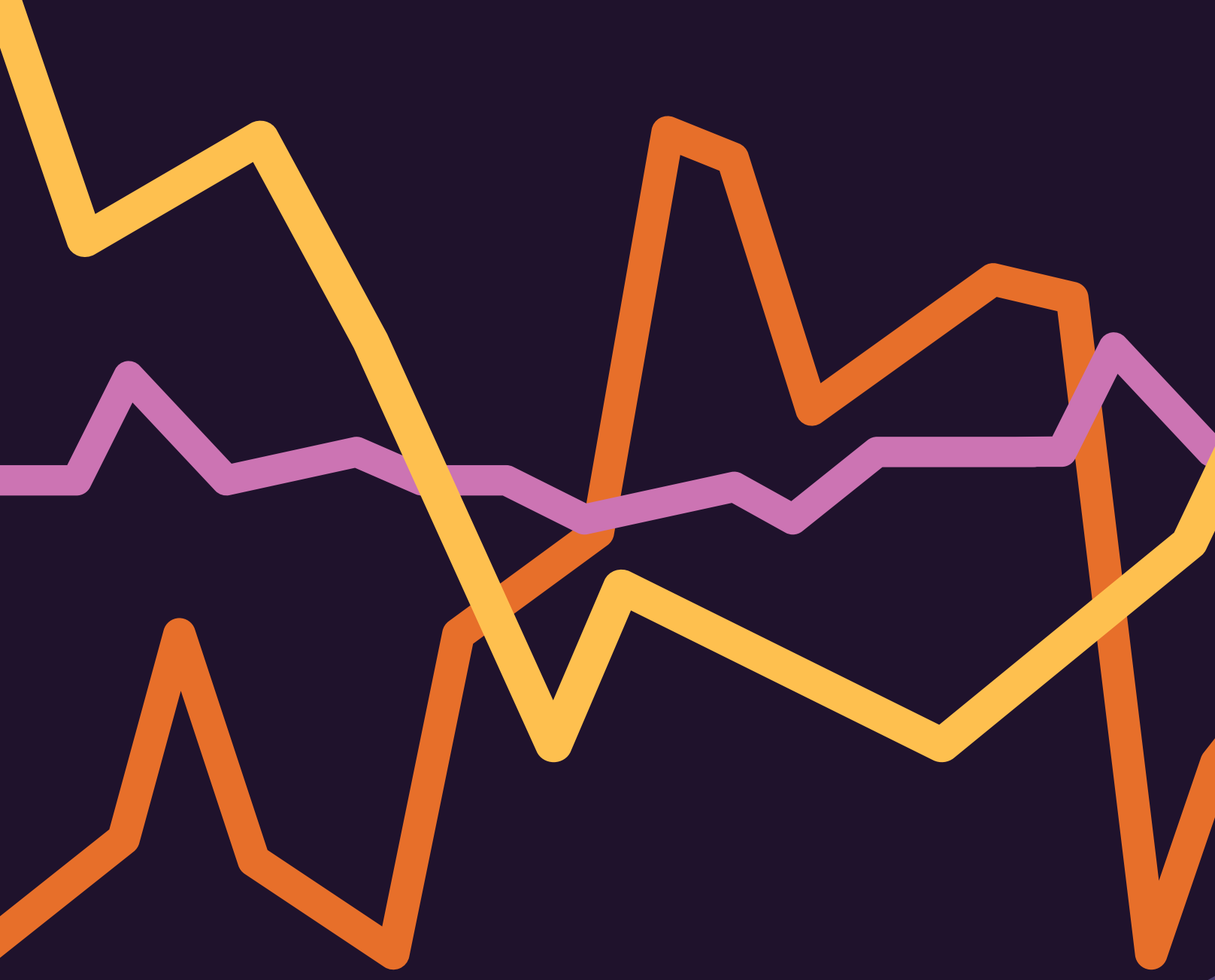


\title{
Geoid Heights in Costa Rica, Case of Study: Baseline Along the Central Pacific Zone
}

\section{Alturas Geoidales en Costa Rica, caso de estudio: Línea base a lo largo de la Zona Pacífico Central}

\author{
Alonso Vega Fernández \\ Surveying Engineering School, University of Costa Rica, San José, Costa Rica \\ alonso.vega_f@ucr.ac.cr \\ Oscar H. Lücke Castro \\ Central American School of Geology, University of Costa Rica, San José, Costa Rica \\ oscar.luckecastro@ucr.ac.cr \\ Jaime Garbanzo León \\ Surveying Engineering School, University of Costa Rica, San José, Costa Rica \\ jaimegarbanzo@gmail.com
}

Recibido: 8 de enero 2019

Aceptado: 23 de setiembre 2019

\begin{abstract}
A precise orthometric height $(\mathrm{H})$ and orthometric height difference $(\Delta \mathrm{H})$ determination is required in many fields like Construction, Geodesy and Geophysics. $\mathrm{H}$ is often obtained from an ellipsoidal height (h) and geoid height (N) of a geopotential model (GM) because this computation does not have the spirit leveling restrictions on long distances. However, the $\mathrm{H}$ accuracy depends on the GM local area adaptation, and current global geopotential models (GGMs) have not been yet evaluated for Costa Rica. Therefore, this paper aims to determine which GGM maintains a better fit with a GPS/levelling baseline that contains the gravity full spectrum. A $74 \mathrm{~km}$ baseline was measured using GPS, spirit leveling and gravity measurements to validate the N computed from EGM2008, EIGEN-6C4, GECO, EGM96, GGM05C and GOCO05C. First, an absolute $\mathrm{N}$ assessment was made, where geoid height from the GGMs $\left(\mathrm{N}^{\mathrm{GGM}}\right)$ were directly compared to the geometric geoid heights $\left(\mathrm{N}^{\text {geo }}\right)$ obtained from GPS and spirit levelling. A bias fit $\left(\mathrm{N}_{\text {bias }}\right)$ was computed from this comparison to the GGMs with respect to the local vertical reference surface $\left(\mathrm{W}_{0}\right)$. This $\mathrm{N}_{\text {bias }}$ value differs from model to model but the best fit is given by GECO. By subtracting the $\mathrm{N}_{\text {bias }}$, a relative geoid height $(\Delta \mathrm{N})$ assessment was designed to compare the differences between GGM relative geoid height $\left(\Delta \mathrm{N}^{\mathrm{GGM}}\right)$ and geometric relative geoid height $\left(\Delta \mathrm{N}^{\text {geo }}\right)$ on segments along the baseline. The $\Delta \mathrm{N}$ comparison shows that EGM2008, EIGEN-6C4 and GECO better represent the Costa Rican Central Pacific Coastal Zone and over long distances, $\Delta \mathrm{H}$ can be computed with a decimeter to centimeter precision.
\end{abstract}

Keywords:

Geodesy, Geoid, Geodetic Levelling, Ortometric Hight, Hight Systems. 


\section{Resumen}

La determinación de alturas ortométricas $(\mathrm{H})$ y diferencias de altura ortométrica $(\Delta \mathrm{H})$ precisas es requerida en campos como construcción, geodesia y geofísica. La H puede obtenerse midiendo altura elipsoidal (h) y calculando altura geoidal $(\mathrm{N})$ de un modelo geoidal $(\mathrm{GM})$, evitando limitaciones de la nivelación geodésica en largas distancias. Sin embargo, la precisión de H dependerá de la adaptación del GM al sitio, y la adaptación de los modelos de geopotencial globales (GGMs) actualmente se desconoce para Costa Rica. Por tanto, el presente artículo busca determinar cuál GGM mantiene mayor congruencia con una línea base de GPS / Nivelación que contenga el espectro de gravedad completo. Para esto, se midió una línea base de 74 km utilizando GPS, nivelación geodésica y mediciones gravimétricas, para validar el N calculado con EGM2008, EIGEN-6C4, GECO, EGM96, GGM05C y GOCO05C. Primero, se evaluó el valor absoluto de N, donde $\mathrm{N}$ de los GGMs ( $\left.\mathrm{N}^{\mathrm{GGM}}\right)$ se comparó directamente con $\mathrm{N}$ geométrica $\left(\mathrm{N}^{\mathrm{geo}}\right)$ obtenida con GPS y nivelación geodésica. Se obtuvo un sesgo $\left(\mathrm{N}_{\text {bias }}\right)$ de los GGMs respecto de la superficie de referencia vertical local $\left(\mathrm{W}_{0}\right)$. Este valor difiere de modelo a modelo, pero GECO se ajusta más a la zona. Al sustraer el Nbias, se aplicó una evaluación de la altura geoidal relativa $\left(\Delta \mathrm{N}^{\mathrm{GGM}}\right)$ respecto de la altura geoidal geométrica relativa $\left(\Delta \mathrm{N}^{\mathrm{geo}}\right)$ en segmentos a lo largo de la línea base. La comparación de $\Delta \mathrm{N}$ mostró que EGM2008, EIGEN-6C4 y GECO representan de mejor forma la zona costera del Pacífico Central de Costa Rica, y que en largas distancias es posible obtener $\Delta \mathrm{H}$ con precisiones decimétricas a centimétricas.

\section{Palabras clave:}

Geodesia, Geoide, Nivelación, Nivelación Geodésica, Altura Ortométrica, Sistemas de Altura. 


\section{INTRODUCTION}

A precise determination of an orthometric height $(\mathrm{H})$ is required in many fields like Construction, Geodesy and Geophysics. Orthometric heights are often obtained using the GNSS positioning technique and a geopotential model to replace conventional leveling techniques because there is no restriction in distances, and spirit leveling can be time-consuming. For these reasons, the behavior of these models, in terms of accuracy, is always a concern. Geopotential models (GMs) are used to correct ellipsoidal heights (h) value, which allows to obtain an $\mathrm{H}$ because it can supply a geoid height $(\mathrm{N})$. This $\mathrm{N}$ value is a difference between $\mathrm{h}$ and $\mathrm{H}$ that occurs because of the heterogeneities in distribution of Earth's masses (Vaníček, Kingdon, \& Santos, 2012).

There are many Global Geopotential Models (GGMs) such as the EGM2008, EIGEN-6C4, GECO (Förste et al., 2014; Gilardoni, Reguzzoni, \& Sampietro, 2016; Pavlis, Holmes, Kenyon, $\&$ Factor, 2012), which provide high global accuracy. However, these accuracies are derived from error estimates of the least squares adjustment results called "internal error" and the challenge lies on the determination of the "external error" (Gruber, 2004). The external error determines how similar is a GM to the real geoid. Thus, a GGM sometimes does not provide a good representation for local areas, especially if the GGM does not have terrestrial or aerial gravity of the local area. Consequently, there are adaptations of the models for local areas which provides a more precise representation (Sánchez, 2003; Sobrino, Mourón, \& Fernández, 2009). However, this situation is not the case for some developing countries in Central America and among them Costa Rica.

Currently, there is no local GM adapted to Costa Rica, and the performance of GGMs has not yet been evaluated in detail for the country. Köther et al. (2012) provide a regional evaluation of EGM2008 in terms of gravity anomalies compared to surface gravity data. Moreover, there has been also an attempt to measure the quality of the OSU-91A by comparing a N computed from GPS measurements and known H Benchmarks (BMs) of the National Geographic Institute (Diaz, 1997). However, it was found that these $\mathrm{N}$ were not comparable, and a quality measure could not be done. There were studies carried out on local geoid determination (Cordero, 2010; Moya \& Dörries, 2016) but the areas taken into account for these studies were less than $50 \mathrm{~km}^{2}$. Thus, the fit of different geoid models in most of the country remains unknown.

GNSS measurements and spirit leveling are frequently used for quality assessment by computing a geometric $\mathrm{N}\left(\mathrm{N}^{\text {geo }}\right)$. This GNSS measurements are available with their respective $(\mathrm{H})$ in areas such as United States, Canada, Japan, Brazil and the European Countries. In addition, GGMs accuracy determination studies are abundant.

For instance, Gruber (2009) tested EGM08, EGM96 and other GGMs in Canada, Japan, and Europe; Szúcs (2012) compared GOCE and GRACE derived models to GNSS/H corrected with EGM08 to match the spectral contents; Guimarães et al. (2012) assessed various models for the State of Sao Pablo, Brazil. All these studies either tried to match the spectral contents or estimate an omission error for each model. 
Regarding, Kotsakis and Katsambalos (2010), they used the full spectral contents of the GNSS/H to evaluate EGM08, EGM96 and other EIGEN derived models and, they found a bias after a least-squares determination. This bias was corrected to compare the different studied models. Although to match the spectral contents of the model is a more rigorous approach, the full spectrum of gravity effects is contained in measurements in practical applications. Thus, scientist, engineers, geographers and other common GGM users could chose a determined GGM model knowing what uncertainties are in their measurements.

Consequently, this paper aims to determine which geoid maintains a better fit with a GPS/ leveling baseline that contains the full spectrum of gravity contents for engineers and researchers having better criteria for choosing between GGMs for their application. Also, GPS/leveling baseline was independently measured to avoid problems presented by other studies (Cordero, 2010; Diaz, 1997; Moya \& Dörries, 2016), which relied on the erroneous local leveling network or studied a small area to be compared to GGMs.

\section{METHODS}

\subsection{Data collection}

The required data for this evaluation is: latitude, longitude, ellipsoidal height, spirit leveling and gravity measurements. These data are used as listed below.

1. GNSS latitude $(\phi)$ and longitude $(\lambda)$ are used to obtain the geoid heights for each GGM $\left(\mathrm{N}^{\mathrm{GGM}}\right)$.

2. Orthometric heights $(\mathrm{H})$ are obtained from gravity measurements, spirit leveling, and a known point referred to the mean see level.

3. A geometric $\mathrm{N}\left(\mathrm{N}^{\mathrm{geo}}\right)$ can be computed from an ellipsoidal height $(\mathrm{h})$ and a $\mathrm{H}$.

These GNSS measurements were obtained on 6 BMs set along $74 \mathrm{~km}$ of the Central Pacific of Costa Rica; two GNSS receivers (Dual-frequency Topcom GR-3) collected the data simultaneously using the relative static method. This technique allows to have a correlation between the two receivers to calculate relative position with the highest precision in data post-processing. Even, it is use to determine geometric height difference referred to an ellipsoid (Instituto Geográfico Agustín Codazzi, 1997).

The field survey was planned in order to measure a GNSS baseline during at least 1 hour of continuous observation on two consecutive BMs. One of the receivers remains in observation while the other receiver is transferred to the next BM to link the consecutive GNSS baselines. In all cases, a $15^{\circ}$ elevation cut-off angle, PDOP values of less than 7 , and 15 seconds sampling rate were used in data collection. The data post-processing took into account the IGS precise orbits (epoch: 2016.270) with respect to the WGS84 ellipsoid (National Imagery and Mapping Agency, 1997) 
Moreover, several GGMs (see Table 1) were chosen based on the following selection criteria: the popularity, the geoid model maximum degree $\left(\ell_{\max }\right)$, maximum spatial resolution $\left(\psi_{\max }\right)$ and the satellite missions used for its calculation. Most are recent GGMs that have been developed with combined satellites missions, satellite altimetry data, and some GGMs have terrestrial gravity data. The International Centre for Global Earth Models (ICGEM) provided these GGMs, which can be downloaded from the online computation platform, where $\mathrm{N}$ is determined from the height anomaly plus spherical shell approximation of the topography (Barthelmes, 2013). The calculation service uses a web-interface (http://icgem.gfz-potsdam.de/) to calculate gravity field functionals from the spherical harmonic models on grids (for this study, grids are referring to WGS84, and unmodified model tide system). In order to obtain a $\mathrm{N}$ for each GGM in the exact location a script was programed to apply an Inverse Distance Weighted Interpolation (IDW) on the grid.

Table 1. GGMs used on N evaluation.

\begin{tabular}{ccccc}
\hline GGM & $\ell_{\max }$ & $\psi_{\max }(\mathrm{km})$ & Data & Reference \\
\hline EGM2008 & 2190 & 9.132 & $\mathrm{~S}$ (Grace), G, A & (Pavlis et al., 2012) \\
EIGEN-6C4 & 2190 & 9.132 & $\mathrm{~S}$ (Goce, Grace, Lageos), G, A & (Förste et al., 2014) \\
GECO & 2190 & 9.132 & $\mathrm{~S}$ (Goce), EGM2008 & (Gilardoni et al., 2016) \\
EGM96 & 360 & 55.556 & $\mathrm{~S}, \mathrm{G}, \mathrm{A}$ & (Lemoine et al., 1998) \\
GGM05C & 360 & 55.556 & $\mathrm{~S}$ (Grace, Goce), G, A & (Ries et al., 2016) \\
GOCO05C & 720 & 27.778 & $\mathrm{~S}, \mathrm{G}, \mathrm{A}$ & (Fecher, Pail, \& Gruber, \\
\end{tabular}

The EGM2008 is a high resolution GGM that has been well studied worldwide, showing good results for many regions (Dawod, Mohamed, \& Ismail, 2009; Gruber, 2009; Kotsakis \& Katsambalos, 2010; Łyszkowicz, 2009). EIGEN-6C4 and GECO use the EGM2008 terrestrial gravimetric data as calculation input thus there is a correlation between these GGMs.

Furthermore, both EIGEN-6C4 and GECO also include satellite data that was not available for EGM2008, so the comparison of the N results with these GGM is necessary. The GECO geoid model combines the GOCE satellite-only global model and EGM2008 to improve the model accuracy in the low to medium wavelengths in some areas (Gilardoni et al., 2016). EIGEN-6C4 uses LAGEOS, GRACE and GOCE satellite data and incorporates an EGM2008 geoid height grid for the continents (Förste et al., 2014). 
In the case of the spirit leveling, it was carried out following the NOAA standards to match the maximum precision (NOAA, 1981, 1995), except for the staff material because of resource limitations. NOAA requires IDS (Invar Doubled Scale) but a bar-code metal staff was used. This staff add some uncertainties associated with thermal expansion. Moreover, the automatic level used in this study was a Leica Sprinter 250M. The accuracy of the instruments used in spirit leveling was verified with ISO 17123-2:2001 test (International Organization for Standarization, 2001).

It was necessary to use gravity measurements in order to apply orthometric corrections to the levelling height differences along the baseline. These corrections can be found in the work of Kao and Ning (2008). The gravity survey was carried out with a relative Burris gravity meter (B-106). The survey started on a known gravity value of a station at University of Costa Rica (UCR) to set up a secondary gravity station near to the baseline middle, on the EST BM (see Figure 1). The gravity values were translated to the other stations.

The initial and final measurements of the gravity campaign were made on the gravity station at UCR, and three others were performed on the secondary station (EST). Both procedures were made to control the instrumental drift and the effects caused by atmospheric pressure changes (Seigle, 1995).

Finally, observed gravity values were corrected to get the gravity value on the ground surface. The corrections related with variation in latitude and elevation were applied on the field. Other as earth tides correction and instrument drift correction were applied after the measurement works.

For each BM, the $\mathrm{N}^{\text {geo }}$ was calculated applying Equation 1 (Hofmann-Wellenhof \& Moritz, 2006).

$$
N^{g e o}=h-H
$$

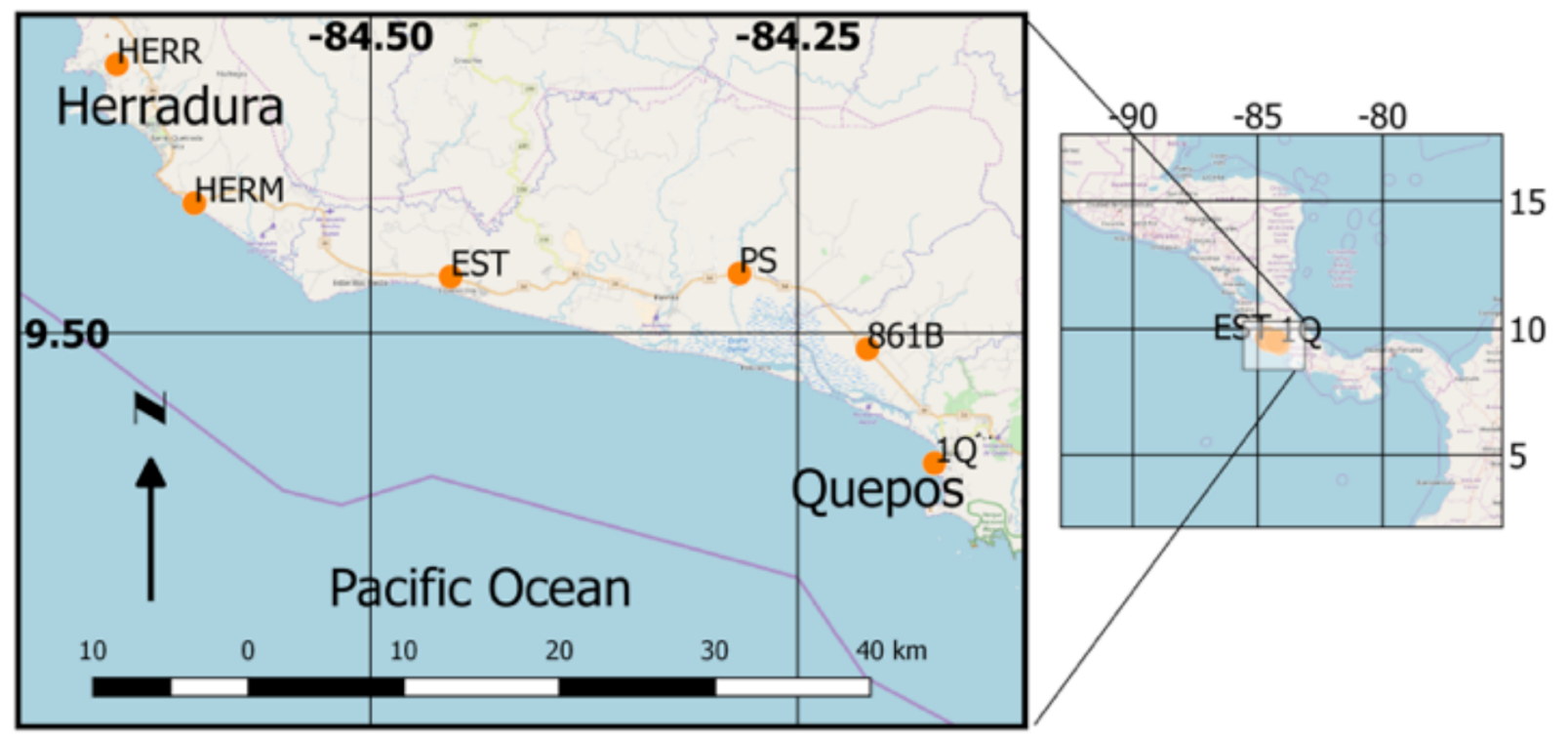

Figure 1. The BM distribution in the Central Pacific Coastal Zone. Coordinates are shown in WGS84. 
The $\mathrm{h}$ values were obtained as described above, and $\mathrm{H}$ of the BMs with the orthometric height differences $(\Delta \mathrm{H})$ measurements. The orthometric heights were referred to the National Vertical Network reference frame ( $\mathrm{W}_{0}$ unknown). The vertical geodetic datum of Costa Rica was referred to a mean sea level calculated in the Puntarenas' port, using tide-gauge measurements during the period between 1942 - 1969 (Camacho, 1997).

These values provide the dataset for the GGMs evaluation. The GGMs omission error was not estimated, applying an evaluation with unmodified GGMs. In addition, the BMs distribution on the Central Pacific Coastal Zone are shown in Figure 1.

\subsection{Assessment of the GGMs}

For the $\mathrm{N}^{\mathrm{GGM}}$ assessment, there are two methods to determine the GGM performance in terms of accuracy. In the first one, an absolute $\mathrm{N}$ assessment was carried out where $\mathrm{N}^{\mathrm{GGM}}$ values were directly compared with the $\mathrm{N}^{\text {geo }}$ values. The subtraction of these two values results in an approximation of the bias from GGMs respect to the local vertical reference $\left(\mathrm{N}_{\text {bias }}\right)$ as shown in Equation 2. For the second method, a relative geoid height $(\Delta N)$ assessment was designed to compare the differences between relative values of segments along the baseline (S). The $\Delta$ Ns were computed subtracting values from the same dataset taking one point as reference (see Equation 3) and depending on the separation of the benchmarks in order to assess the GGMs behavior with different baseline lengths.

$$
\begin{gathered}
N_{\text {bias }}=N^{G G M}-N^{g e o} \\
\Delta N_{i j}^{G G M}=N_{j}^{G G M}-N_{i}^{G G M}
\end{gathered}
$$

In the case of $\Delta \mathrm{N}^{\text {geo }}$, this calculation uses the height differences between two BMs based on height systems relationship of Equation 1, using orthometric and ellipsoidal height difference to obtain Equation 4 (Hirt et al., 2011; Torge \& Müller, 2012).

$$
\Delta N_{i j}^{g e o}=\Delta h_{i j}-\Delta H_{i j}
$$

Then, the relative geoid height $(\Delta \mathrm{N})$ assessment uses the residuals between $\Delta \mathrm{N}^{\mathrm{GGM}}$ and $\Delta \mathrm{N}^{\text {geo }}$ $\left(\Delta \mathrm{N}^{\mathrm{GGM}-\text { geo }}\right)$ as shown in Equation 5.

$$
\Delta N^{G G M-g e o}=\Delta N^{G G M}-\Delta N^{g e o}
$$

\subsection{Statistical testing}

When comparing two different datasets, it is highly relevant to know whether these datasets have the same precision. Thus, an F-test of equality of the variances must be performed. The null 
hypothesis of these test, states that the variances are statistically similar and follow the relation shown by Equation 6 .

$$
H_{0}: \frac{S_{1}^{2}}{S_{2}^{2}}=1
$$

where $S_{1}$ y $S_{2}$ are the sample variances with $S_{1}>S_{2}$.

This hypothesis can be rejected when F, computed from Eq 6, is larger than the critical value $\left(\mathrm{F}_{\alpha}\right)$, computed from the Fisher distribution (Ghilani, 2011).

First, this F-test of equality of the variances was used in order to test if the differences in the geoid heights $\left(\Delta \mathrm{N}^{\mathrm{GGM}-\mathrm{geo}}\right)$ are comparable between geoids, which provides some criteria to decide which model performs better.

Second, if the null hypothesis $\left(\mathrm{H}_{0}\right)$ is accepted, a two sampled t test is performed to know if the $\Delta \mathrm{N}^{\mathrm{GGM}-\mathrm{geo}}$ means are significantly different. This test is computed from Equations 7 and 8.

$$
\begin{aligned}
t & =\frac{\left(\overline{x_{1}}-\overline{x_{2}}\right)}{s_{p} \sqrt{\frac{1}{n_{1}}+\frac{1}{n_{2}}}} \\
S_{p} & =\frac{\left(n_{1}-1\right) * S_{1}^{2}+\left(n_{1}-1\right) * S_{2}^{2}}{n_{1}+n_{2}-2}
\end{aligned}
$$

where $n_{1}$ and $n_{2}$ are the sample sizes; $S_{1}$ and $S_{2}$ are the standard deviations; $\overline{x_{1}}$ and $\overline{x_{2}}$ are the means for sample 1 and sample 2 respectively.

$\mathrm{H}_{0}$ of this test states that the differences of the mean population are $0\left(\left(\mu_{1}-\mu_{2}\right)=0\right)$; The non-equality of the means is chosen as $\mathrm{H}_{\mathrm{a}}$ (Ayyub \& McCuen, 2011).

\subsection{RMS quality assessment}

An alternative quality assessment can be performed by computing the root mean squared (RMS), where the residuals are the $\Delta \mathrm{N}^{\mathrm{GGM}-\mathrm{geo}}$ values. The RMS is computed using Equation 9.

$$
R M S=\sqrt{\frac{\sum r_{i}^{2}}{n}}
$$

The RMS values can be computed for each baseline length. In addition, all residuals for every baseline length can be computed in order to obtain a global RMS value, which shows the GGM $\left(\Delta \mathrm{N}^{\mathrm{GGM}}\right)$ fit relative to the standard of comparison $\left(\Delta \mathrm{N}^{\mathrm{GGM} \text {-geo }}\right)$. 


\section{RESULTS AND ANALISIS}

\subsection{Absolute Assessment}

There are two alternatives to determine the GGMs characteristics (see the Assessment of the GGMs section). The first alternative implies the existence of a bias fit while the second one implies the removal of this bias. First, we assess the absolute bias of the evaluated models. Table 2 presents the different heights obtained to each BM along the baseline that were necessary to $\mathrm{N}^{\text {geo }}$ calculation. $\mathrm{H}$ values are referred to Costa Rica's official vertical network.

Table 2. The $H$, $h$ and $N^{\text {geo }}$ values obtained to each $B M$; the results are given in meters.

\begin{tabular}{ccccccc}
\hline BM & $\mathrm{h}$ & $\sigma$ & $\mathrm{H}$ & $\sigma$ & $\mathrm{N}$ & $\sigma$ \\
\hline 1Q & 16.516 & \pm 0.011 & 4.8832 & \pm 0.000 & 11.6328 & \pm 0.011 \\
861B & 18.011 & \pm 0.000 & 6.2869 & \pm 0.004 & 11.7241 & \pm 0.004 \\
PS & 24.291 & \pm 0.008 & 13.0252 & \pm 0.006 & 11.2658 & \pm 0.010 \\
EST & 18.641 & \pm 0.014 & 8.2167 & \pm 0.008 & 10.4243 & \pm 0.016 \\
HERM & 16.475 & \pm 0.019 & 6.0694 & \pm 0.011 & 10.4056 & \pm 0.022 \\
HERR & 21.089 & \pm 0.022 & 10.5023 & \pm 0.011 & 10.5867 & \pm 0.026 \\
\hline
\end{tabular}

Table 3. GNSS position of each BM in the baseline.

\begin{tabular}{ccc}
\hline BM & LAT & LON \\
\hline 1Q & $09^{\circ} 25^{\prime} 29.31309^{\prime \prime}$ & $-84^{\circ} 10^{\prime} 12.36605^{\prime \prime}$ \\
861B & $09^{\circ} 29^{\prime} 27.03686^{\prime \prime}$ & $-84^{\circ} 12^{\prime} 33.26513^{\prime \prime}$ \\
PS & $09^{\circ} 32^{\prime} 03.28487^{\prime \prime}$ & $-84^{\circ} 17^{\prime} 03.33745^{\prime \prime}$ \\
EST & $09^{\circ} 31^{\prime} 56.93949^{\prime \prime}$ & $-84^{\circ} 27^{\prime} 11.30845^{\prime \prime}$ \\
HERM & $09^{\circ} 34^{\prime} 29.53570^{\prime \prime}$ & $-84^{\circ} 36^{\prime} 11.46800^{\prime \prime}$ \\
HERR & $09^{\circ} 39^{\prime} 17.77866^{\prime \prime}$ & $-84^{\circ} 38^{\prime} 54.46786^{\prime \prime}$ \\
\hline
\end{tabular}


Table 4. $N^{G G M}$ values obtained whit each GGM; the results are given in meters.

\begin{tabular}{ccccccc}
\hline BM & EGM96 & EGM2008 & EIGEN-6C4 & GECO & GGM05C & GOCO05C \\
\hline 1Q & 11.5056 & 11.7567 & 11.6115 & 11.6056 & 12.3335 & 11.7497 \\
861B & 11.6954 & 11.8427 & 11.6807 & 11.6675 & 12.5576 & 12.0240 \\
PS & 11.4139 & 11.4343 & 11.2550 & 11.2502 & 12.1767 & 11.7127 \\
EST & 10.3639 & 10.5824 & 10.4121 & 10.4183 & 10.8111 & 10.6738 \\
HERM & 10.0183 & 10.5157 & 10.3615 & 10.3889 & 10.2546 & 10.3479 \\
HERR & 10.3644 & 10.8089 & 10.6561 & 10.7087 & 10.5956 & 10.5072 \\
\hline
\end{tabular}

Table 5. Differences between $N^{\text {geo }}$ and $N^{G G M}\left(N_{\text {bias }}\right)$, and mean bias approximation; the results are given in meters.

\begin{tabular}{lcccccc}
\hline BM & EGM96 & EGM2008 & EIGEN-6C4 & GECO & GGM05C & GOCO05C \\
\hline 1Q & -0.127 & 0.124 & -0.021 & -0.027 & 0.701 & 0.117 \\
861B & -0.029 & 0.119 & -0.043 & -0.057 & 0.834 & 0.300 \\
PS & 0.148 & 0.169 & -0.011 & -0.016 & 0.911 & 0.447 \\
EST & -0.060 & 0.158 & -0.012 & -0.006 & 0.387 & 0.250 \\
HERM & -0.387 & 0.110 & -0.044 & -0.017 & -0.151 & -0.058 \\
HERR & -0.222 & 0.222 & 0.069 & 0.122 & 0.009 & -0.079 \\
\hline Bias fit & -0.113 & 0.15 & -0.01 & 0 & 0.449 & 0.106 \\
\hline STD & 0.182 & 0.042 & 0.042 & 0.062 & 0.443 & 0.173 \\
\hline
\end{tabular}

Moreover, the positions for this study where obtained Fixing the 861B BM point in a relative static post-process (see Table 3). The 861B position was computed using the NRCAN-PPP service (https://webapp.geod.nrcan.gc.ca/geod/tools-outils/ppp.php). A centimetric accuracy of these positions is enough, since the geoid is a very smooth surface and the maximum resolution of a GGM is about $9 \mathrm{~km}$. This information was needed to calculate the $\mathrm{N}^{\mathrm{GGM}}$ shown in Table 4. 
The mean value of the subtraction of $\mathrm{N}^{\mathrm{GGMs}}$ and $\mathrm{N}^{\text {geo }}$ results in the least-squares constant bias value for each GGM as shown in Table 5. These values show that this vertical offset varies from model to model. However, EIGEN-6C4 and GECO fit the best to this leveling base line.

Likewise, this result shows the influence of the degree and order of a model despite the smooth variation of the pacific leveling baseline. The small bias fit of EIGEN-6C4 and GECO is an evidence of the improvement made with the inclusion of GOCE data. Figure 2 shows a box-whisker chart, where the distribution of the values can be better seen. Despite these results, the determination of a bias fit for the whole country remains as an open question because a better distribution and a greater number of samples are needed.

Authors state that a bias is an indicator of error in the geopotential model spherical harmonic coefficients (Kotsakis \& Katsambalos, 2010; Łyszkowicz, 2009). Figure 3 shows a pot of the N values, which describe better the behavior among the models and the local orthometric height datum with unknown geopotential reference value $\left(\mathrm{W}_{0}\right)$. This approximation of the bias fit gives a better understanding of the reference surface used in the old Costa Rican height system.

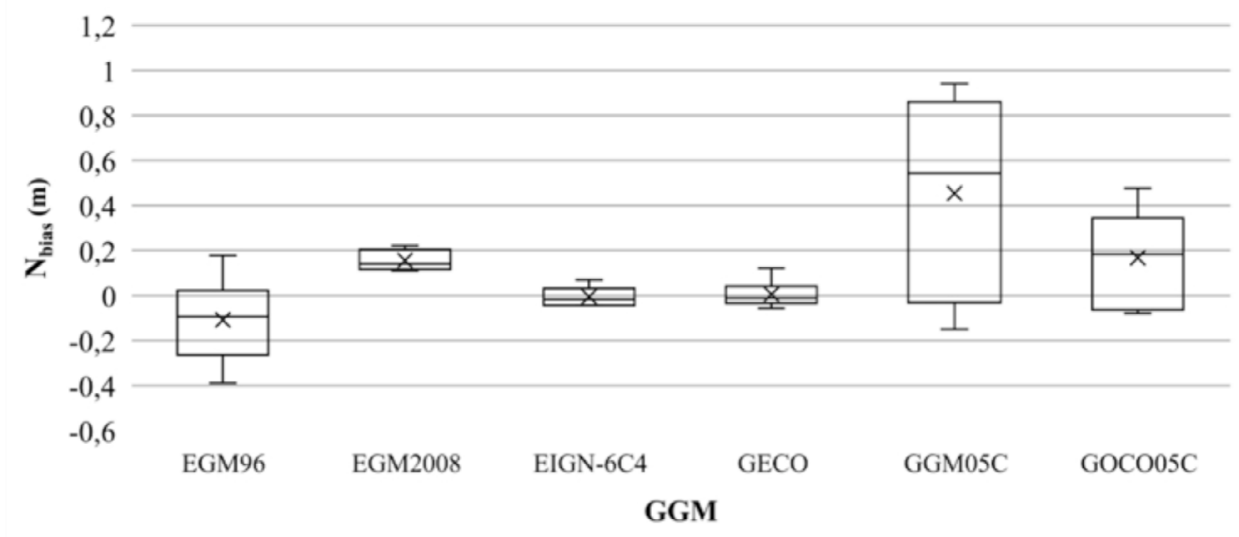

Figure 2. Bias for the GGMs in meters.

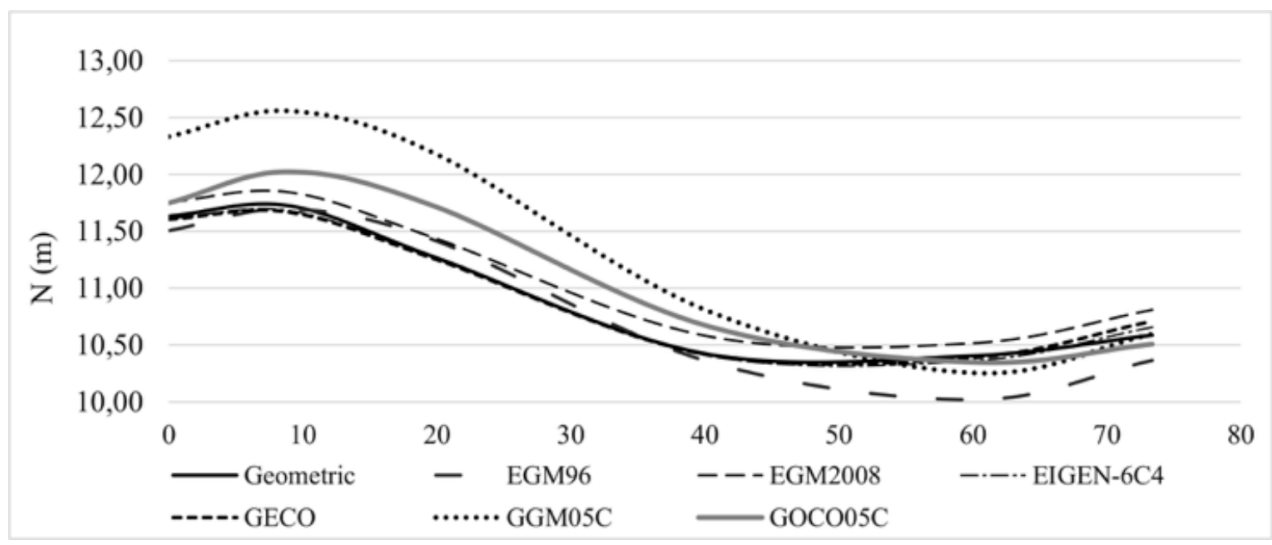

Figure 3. A no significant vertical offset is shown between local reference geoid ( $\mathrm{W}_{0}$ unknown) and evaluated GGMs. 


\subsection{Relative Assessment}

The other method for the evaluation of GGMs is the removal of the bias by computing the differences in $\mathrm{N}(\Delta \mathrm{N})$. Here, the differences of the $\Delta \mathrm{Ns}$ subtraction (Equation 5) were analyzed for all possible baseline lengths, grouping these residuals into different separation length categories ( $<20 \mathrm{~km}, 21$ to $40 \mathrm{~km}, 41$ to $65 \mathrm{~km})$.

Table 6. $\Delta N^{G G M-g e o}$ values with $<20 \mathrm{~km}$ baselines length, mean $(\mathrm{m})$ and standard deviation $(S)$ of each $G G M$; the results are given in meters.

\begin{tabular}{ccccccc}
\hline Baseline & EGM96 & EGM2008 & EIGEN-6C4 & GECO & GGM05C & GOCO05C \\
\hline 1Q - 861B & 0.098 & -0.005 & -0.022 & -0.029 & 0.133 & 0.183 \\
861B - PS & 0.177 & 0.050 & 0.033 & 0.041 & 0.077 & 0.147 \\
1Q - PS & 0.275 & 0.045 & 0.011 & 0.012 & 0.210 & 0.330 \\
PS - EST & -0.208 & -0.010 & -0.001 & 0.010 & -0.524 & -0.197 \\
EST - HERM & -0.327 & -0.048 & -0.032 & -0.011 & -0.538 & -0.307 \\
HERM - HERR & 0.165 & 0.112 & 0.114 & 0.139 & 0.160 & -0.022 \\
\hline m & 0.030 & 0.024 & 0.017 & 0.027 & -0.080 & 0.022 \\
\hline S & 0.240 & 0.057 & 0.053 & 0.060 & 0.352 & 0.243 \\
\hline
\end{tabular}

Table 7. Fisher test on the variance $\left(S^{2}\right)$ for $\Delta N^{G G M-g e o}$ values of $<20 \mathrm{~km}$ baseline length .

\begin{tabular}{lccccc}
\hline & EGM2008 & EIGEN-6C4 & GECO & GGM05C & GOCO05C \\
\hline EGM96 & 17.99 & 20.69 & 16.18 & 2.14 & 1.02 \\
EGM2008 & & 1.15 & 1.11 & 38.56 & 18.36 \\
EIGEN-6C4 & & 1.28 & 44.36 & 21.12 \\
GECO & & & 34.69 & 16.52 \\
GGM05C & & & & 2.10 \\
\hline
\end{tabular}

Critical value $\left(\mathrm{F}_{95}\right)=5.05$; Degree freedom $(\mathrm{n}-1)=5$ 
In some cases, these separation lengths were less than the maximum spatial resolution $\left(\psi_{\max }\right)$. For instance, EGM96 and GGM05C have a $\psi_{\max }$ greater than $55 \mathrm{~km}$, which is longer than most baselines. However, these baselines still provide useful data for studying the geoid surface behavior. On the other hand, the overall precision estimated by $\psi_{\max }$ is not absolute for the GGM's entire surface, since the data accuracy depends largely on the degree of the adaptation of the evaluated area (Vanícek, Santos, Tenzer, \& Hernández-Navarro, 2003). Despite this, the maximum degree and order for each model is evaluated since knowledge of the error of the GGMs is important for precise applications.

Table 6 shows the differences (Equation 5) of the values calculated for the baselines that are less than $20 \mathrm{~km}$. The mean $(\mathrm{m})$ of $\Delta \mathrm{N}^{\mathrm{GGM} \text {-geo }}$ is expected to be 0 because the $\Delta \mathrm{N}$ are free from the biases and the substation $\left(\Delta \mathrm{N}^{\mathrm{GGM}-\mathrm{geo}}\right)$ should reflect a normal distribution. The results shown in Table 6 vary from a few mm (e.g. EGM2008/EIGEN-6C4), to more than half a meter (e.g. GGM05C).

The lowest mean value is obtained for EIGEN-6C4, where $\mathrm{m}=1.72 \mathrm{~cm}$ and $\mathrm{S}=5.28 \mathrm{~cm}$. However, EGM2008 and GECO also have similar values. Thus, a fisher test is performed to assure the comparison of values with the same precision (see Table 7$)$. The test on variances $\left(\mathrm{S}^{2}\right)$ separate the GGMs into two groups which are statistically similar.

The first group contains EGM2008, EIGEN-6C4 and GECO, the second one contains the EGM96, GGM05C, GOGO05C. The first group contains the lowest standard deviation therefore we infer that this group should have a better fit with the values obtained for the baseline measured geometrically with gravity corrections.

Table 8. $\Delta N^{G G M-g e o}$ values of 21 to $40 \mathrm{~km}$ baselines length, mean $(\mathrm{m})$ and standard deviation $(S)$ of each GGM; the results are given in meters.

\begin{tabular}{ccccccc}
\hline Baseline & EGM96 & EGM2008 & EIGEN-6C4 & GECO & GGM05C & GOCO05C \\
\hline 861B - EST & -0.032 & 0.039 & 0.031 & 0.051 & -0.447 & -0.050 \\
1Q - EST & 0.067 & 0.034 & 0.009 & 0.021 & -0.314 & 0.133 \\
PS - HERM & -0.535 & -0.058 & -0.033 & -0.001 & -1.062 & -0.505 \\
EST - HERR & -0.162 & 0.064 & 0.082 & 0.128 & -0.378 & -0.329 \\
\hline m & -0.166 & 0.020 & 0.022 & 0.050 & -0.550 & -0.188 \\
\hline S & 0.264 & 0.054 & 0.048 & 0.056 & 0.346 & 0.284 \\
\hline
\end{tabular}

These results for the second group were expected because EGM96 was generated using older data of orbit tracking, ocean topography and surface gravity (Lemoine et al., 1998). On the other 
hand, GGM05C and GOCO05C use fill-in gravity anomalies on the study area (not actual terrestrial gravity data). This lack of terrestrial gravity data implies that these GGMs are able to resolve long-wavelengths based solely on satellite data (Gruber, 2004) which results in high standard deviations for the baseline of $<20 \mathrm{~km}$ (see Table 4).

For the 21 to $40 \mathrm{~km}$ baseline, the models EGM2008, EIGEN-6C4 and GECO still show when comparing them to the other three GGMs (see Table 8 and Table 9). The test on the variances (Table 9) still shows a similar trend to Table 4 but the critical value has increased because a degree of freedom is lost.

Table 9. Fisher test on the variance $\left(S^{2}\right)$ for $\Delta N^{G G M-g e o}$ of 21 to $40 \mathrm{~km}$ baseline length.

\begin{tabular}{cccccc}
\hline & EGM2008 & EIGEN-6C4 & GECO & GGM05C & GOCO05C \\
\hline EGM96 & 24.30 & 30.32 & 21.88 & 1.72 & 1.16 \\
EGM2008 & 1.25 & 1.11 & 41.74 & 28.27 \\
EIGEN-6C4 & & 1.39 & 52.08 & 35.27 \\
GECO & & & 37.58 & 24.45 \\
GGM05C & & & & 1.48 \\
\hline
\end{tabular}

Critical value $\left(\mathrm{F}_{95}\right)=9.28 ;$ Degree freedom $(n-1)=3$

Table 10. $\Delta N^{G G M-g e o}$ of 41 to $65 \mathrm{~km}$ baseline length, mean $(\mathrm{m})$ and standard deviation $(\mathrm{S})$ of each GGM; the results are given in meters.

\begin{tabular}{ccccccc}
\hline & EGM96 & EGM2008 & EIGEN-6C4 & GECO & GGM05C & GOCO05C \\
\hline 861B - HERM & -0.359 & -0.009 & -0.001 & 0.040 & -0.984 & -0.358 \\
1Q - HERM & -0.260 & -0.014 & -0.023 & 0.011 & -0.852 & -0.175 \\
PS - HERR & -0.370 & 0.054 & 0.080 & 0.138 & -0.902 & -0.526 \\
1Q - HERR & -0.095 & 0.098 & 0.091 & 0.149 & -0.692 & -0.196 \\
\hline m & -0.271 & 0.032 & 0.037 & 0.085 & -0.858 & -0.314 \\
\hline S & 0.127 & 0.054 & 0.057 & 0.069 & 0.123 & 0.163 \\
\hline
\end{tabular}


Table 11. Fisher test on the variance $\left(S^{2}\right)$ for $\Delta N^{G G M-g e o}$ of 41 to $65 \mathrm{~km}$ baseline length.

\begin{tabular}{lccccc}
\hline & EGM2008 & EIGEN-6C4 & GECO & GGM05C & GOCO05C \\
\hline EGM96 & 5.63 & 4.96 & 3.38 & 1.07 & 1.65 \\
EGM2008 & & 1.14 & 1.67 & 5.26 & 9.28 \\
EIGEN-6C4 & & 1.47 & 4.63 & 8.17 \\
GECO & & & 3.15 & 5.56 \\
GGM05C & & & & 1.76 \\
\hline
\end{tabular}

Critical value $\left(\mathrm{F}_{95}\right)=9.28$; Degree freedom $(\mathrm{n}-1)=3$

Table 12. Two-sampled t test to determine if two means are statistically similar for the baseline of 41 to $65 \mathrm{~km}$.

\begin{tabular}{cccccc}
\hline & EGM2008 & EIGEN-6C4 & GECO & GGM05C & GOCO05C \\
\hline EGM96 & -4.39 & -4.41 & -4.90 & 6.63 & 0.41 \\
EGM2008 & & -0.11 & -1.19 & 13.26 & 4.02 \\
EIGEN-6C4 & & -1.06 & 13.18 & 4.05 \\
GECO & & & 13.34 & 4.49 \\
GGM05C & & & & -5.32 \\
\hline
\end{tabular}

T value interval $=-2.45,2.45 ; \mathrm{D}$. freedom $(\mathrm{v})=6$

In terms of Table 11, it shows that there are not statistical differences in the variances for baselines from 41 to $65 \mathrm{~km}$. However, the differences in mean values increased for GGM05C, GOCO05C and EGM96 (see Table 10). By applying a two-sampled t test, results show that the computed t values are between the confidence interval when comparing EGM2008, EIGEN-6C4 and GECO (see Table 12). Thus, the null hypothesis that states that these means are statistically equal for these GGMs is accepted.

Moreover, EGM96 shows no statistical difference when compared to GOCO05 for these baseline lengths. The two-sampled t test was also applied to the baselines of $<20 \mathrm{~km}$ and 21 to $40 \mathrm{~km}$ but it doesn't give any important information because the standard deviations of the dataset were high, and the mean is close to 0 (see Table 6 and Table 8). However, it can be stated that there is 
not a significant difference on the mean values for EGM2008, EIGEN-6C4 and GECO in all statistical tests performed.

Another alternative to test the GGMs is evaluating the RMS values and taking the residuals as a subtraction of $\Delta \mathrm{N}^{\text {geo }}$ to $\Delta \mathrm{N}^{\mathrm{GGM}}\left(\Delta \mathrm{N}^{\mathrm{GGM} \text {-geo }}\right)$. If all residuals for the different baseline lengths are combined to compute the RMS, then a global evaluation for each GGM can be performed which provides extra information and validation of the analysis. There is a clear separation of the two GGMs groups; the first group showed RMS values bellow $15 \mathrm{~cm}$ and, the second group showed RMS values above this value (see Table 13). Moreover, GGM05C resulted in the worst RMS, which is twice as much as the closest RMS value obtained for GOCO05C.

Figure 4 shows the RMS, where EGM2008, EIGEN-6C4 and GECO presented the best crosscomparison results for most evaluation cases, with RMS magnitudes similar for each baseline length. These results indicate that the baseline length variation does not significantly change the differences between $\Delta \mathrm{N}^{\text {geo }}$ and $\Delta \mathrm{N}^{\mathrm{GGM}}$ for these GGMs.

Finally, this project is a consequence of a problem that researchers will have when evaluating a GM. The leveling heights from the old altimetric system are unreliable because the accuracy is unknown. Furthermore, this altimetric system is very old and has not been maintained correctly in a country that has strong surface modification because tectonic forces. Therefore, Costa Rica lacks an independent and reliable validation method, which will a high uncertainty when any new GGMs is computed.

Table 13. Global RMS values for all baseline lengths of each GGM. No represents the baseline number; the results are given in meters.

\begin{tabular}{lccccccc}
\hline $\begin{array}{l}\text { Baseline length } \\
(\mathrm{km})\end{array}$ & No & EGM96 & EGM2008 & EIGEN-6C4 & GECO & GGM05C & GOCO05C \\
\hline$<20$ & 6 & 22.1 & 5.7 & 5.1 & 6.1 & 33.1 & 22.3 \\
21 to 40 & 4 & 28.2 & 5.1 & 4.7 & 7.0 & 62.6 & 30.9 \\
41 to 65 & 4 & 29.3 & 5.7 & 6.2 & 10.4 & 86.4 & 34.4 \\
Global & 14 & 26.2 & 5.8 & 5.7 & 8.2 & 58.1 & 29.2 \\
\hline
\end{tabular}




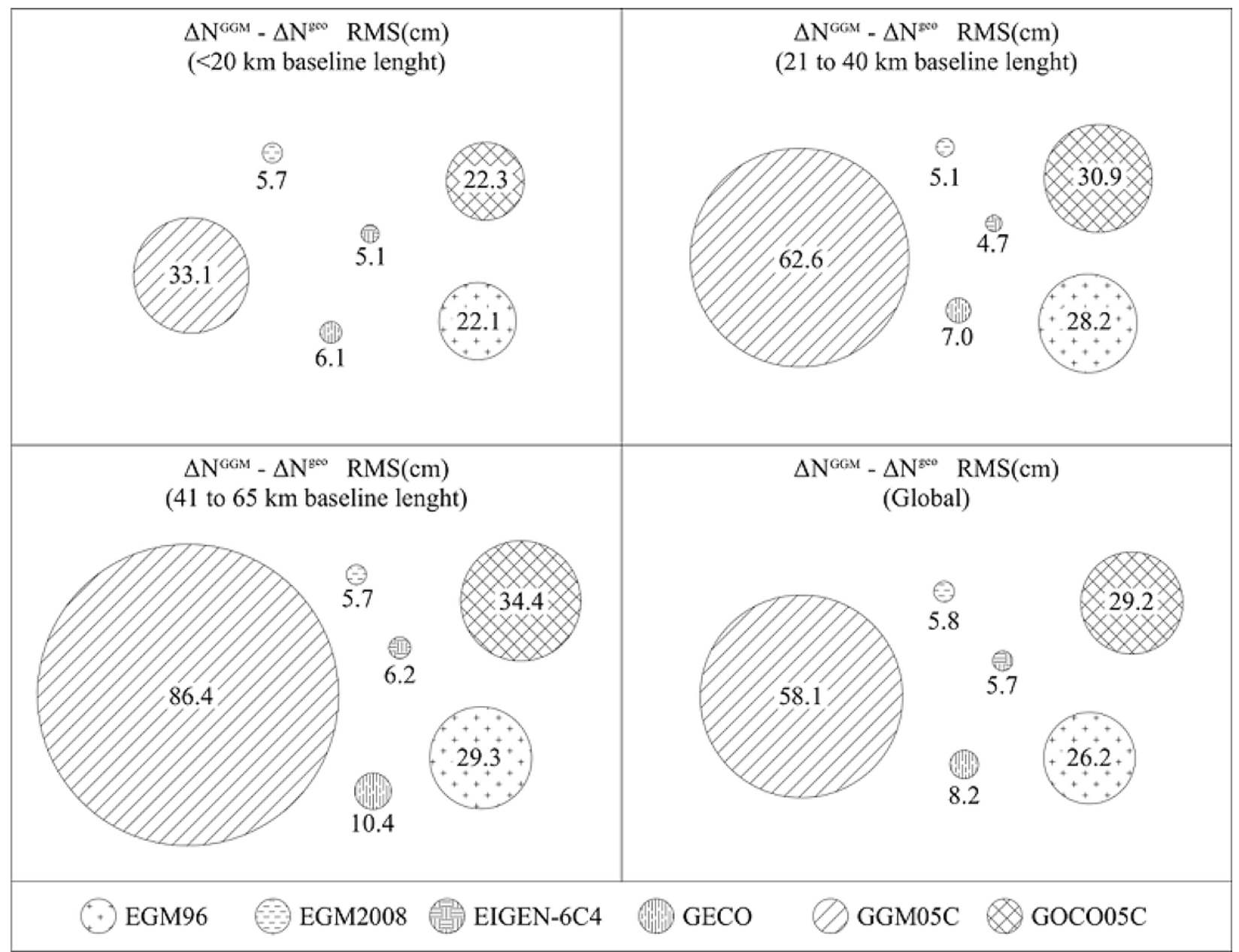

Figure 4. RMS comparison for GGMs for each different long baseline evaluation. EIGEN-6C4 and EGM2008 presented similar RMS values in each case with and, there is an evident of the RMS values for GGMs that are derived solely from satellite data.

\section{CONCLUSIONS}

An approximation of the bias fit $\left(\mathrm{N}_{\text {bias }}\right)$ was computed for global geopotential models (GGMs), which show a correlation with the local reference geopotential value $\left(\mathrm{W}_{0}\right)$ of old local Costa Rican reference datum. The bias fit is not constant among the models; however, the best results are shown by EIGEN-6C4 and GECO. Because of the subtraction of the geometric geoid separation ( $\mathrm{N}^{\text {geo }}$ ) to the GGMs geoid separation (NGGM) is close to 0 and the standard deviation ( $\mathrm{S}$ ) is high for some models, a two-sampled t test will result in a null hypothesis. Consequently, a fisher test on the variance $\left(\mathrm{S}^{2}\right)$ can give information about which geoids are comparable depending on the precision. In baseline from 45 to $65 \mathrm{~km}$, each tested geoid obtains a Fisher value equal or less than the critical value. This means that all tested geoids were equally precise. Thus, a two-sampled test could be applied. This statistical test shows that EGM2008, EIGEN-6C4 and GECO have no significant difference, when comparing the subtraction of the $\Delta \mathrm{N}\left(\mathrm{N}^{\mathrm{GGM}-\mathrm{geo}}\right)$. This tendency is also shown in the graphical representation of the RMS, which can also be good for geoid evaluation. Theoretically, 
after the bias removal, these differences should be 0 if the geoids computed from GGMs are equal to the geometrically computed baseline of the local geoid.

The EGM2008, EIGEN-6C4 and GECO geoid models better represent the Central Pacific Coastal Zone. Also, each of these geoids are more suitable for use in local engineering or scientific projects such as leveling work to obtain orthometric height difference $(\Delta H)$ over long distances with GNSS/levelling technique which requires decimeter to centimeter precision. Finally, more surveys should be done for to have better testing of geoid models for this country because of the lack of reliable leveling data in Costa Rica. This issue will appear whenever a new geoid determination is available.

\section{ACKNOWLEDGMENTS}

The authors would like to thank Survey Engineering School and Central American School of Geology, from University of Costa Rica, for the support during spirit levelling, satellite positioning and gravity measurements.

\section{SYMBOLS}

\begin{tabular}{lc}
\hline GM & Geopotential model \\
GGM & Global Geopotential Model \\
GPS & Global Positioning System \\
H & Ellipsoidal height \\
H & Orthometric height \\
M & Mean \\
N & Geoid height \\
RMS & Root Mean Squared \\
S & Standard deviation \\
$\mathrm{S}^{2}$ & Sample variance \\
$\Delta \mathrm{h}$ & Ellipsoidal height difference \\
$\Delta \mathrm{H}$ & Orthometric height difference \\
$\Delta \mathrm{N}$ & Geoid height difference \\
\hline
\end{tabular}




\section{REFERENCIAS}

Ayyub, B. M., \& McCuen, R. H. (2011). Probability, Statistics, and Reliability for Engineers and Scientists. CRC press.

Barthelmes, F. (2013). Definition of Functionals of the Geopotential and Their Calculation from Spherical Harmonic Models. GFZ Publications (Vol. 104132).

Camacho, J. C. P. (1997). Manual de Cartografía. EUNED.

Cordero, G. (2010). Desarrollo de un modelo geoidal CGV08 como insumo para la determinación nacional del geoide. Uniciencia, 24(1), 35-40.

Dawod, G. M., Mohamed, H. F., \& Ismail, S. S. (2009). Evaluation and Adaptation of the EGM2008 Geopotential Model Along the Northern Nile Valley, Egypt: Case study. Journal of Surveying Engineering, 136(1), 36-40.

Diaz, G. (1997). Estudio de la ondulación del Geoide determinada por nivelación GPS, y la obtenida aplicando el modelo OSU-91A. Universidad Nacional.

Fecher, T., Pail, R., \& Gruber, T. (2016). The Combined Gravity Field Model GOCO05c. In EGU General Assembly Conference Abstracts, 18, 7696.

Förste, C., Bruinsma, S., Abrikosov, O., Flechtner, F., Marty, J.-C., Lemoine, J .-M., ... König, R. (2014). EIGEN-6C4The Latest Combined Global Gravity Field Model Including GOCE Data Up to Degree and Order 1949 of GFZ Potsdam and GRGS Toulouse. In EGU General Assembly Conference Abstracts, 16, 3707.

Ghilani, C. (2011). Adjustment Computations: Spatial Data Analysis. CRC Press.

Gilardoni, M., Reguzzoni, M., \& Sampietro, D. (2016). GECO: A Global Gravity Model by Locally Combining GOCE Data and EGM2008. Studia Geophysica et Geodaetica, 60(2), 228-247.

Gruber, T. (2004). Validation Concepts for Gravity Field Models from New Satellite Missions. In Proceedings of the 2nd International GOCE User Workshop “ GOCE, The Geoid and Oceanography”(Lacoste H., ed.), ESA SP-569.

Gruber, T. (2009). Evaluation of the EGM2008 Gravity Field by Means of GPS-Levelling and Sea Surface Topography Solutions. Newton's Bulletin, 4, 3-17.

Guimarães, G., Matos, A., \& Blitzkow, D. (2012). An evaluation of recent GOCE geopotential models in Brazil. Journal of Geodetic Science, 2(2), 144-155.

Hirt, C., Schmitz, M., Feldmann-Westendorff, U., Wübbena, G., Jahn, C.-H., \& Seeber, G. (2011). Mutual Validation of GNSS Height Measurements and High-Precision Geometric-Astronomical Leveling. GPS Solutions, 15(2), 149-159.

Hofmann-Wellenhof, B., \& Moritz, H. (2006). Physical geodesy. Springer Science \& Business Media.

Instituto Geográfico Agustín Codazzi. (1997). Guía metodológica para la obtención de alturas sobre el nivel medio del mar utilizando el sistema GPS. Retrieved from http://www.igac.gov.co/wps/wcm/connect/5c9cb480469f7a7eb00eb8923ecdf8fe/obtencion+de+alturas+5.pdf?MOD=AJPERES

International Organization for Standarization. (2001). Optics and Optical Instruments - Field Procedures for Testing Geodetic and Surveying Instruments- Part 2: Levels [ISO 17123-2:2001].

Kao, S., \& Ning, F. (2008). The Further Evaluation of Orthometric Correction Using Measured Gravity for Each Set-Up Between Two Benchmarks. Journal of Chung Cheng Institute of Technology, 37(1), 65-70.

Köther, N., Götze, H.-J., Gutknecht, B. D., Jahr, T., Jentzsch, G., Lücke, O. H., .. Zeumann, S. (2012). The Seismically Active Andean and Central American Margins: Can Satellite Gravity Map Lithospheric Structures? Journal of Geodynamics, 59, 207-218. http://doi.org/doi:10.1016/j.jog.2011.11.004

Kotsakis, C., \& Katsambalos, K. (2010). Quality Analysis of Global Geopotential Models at 1542 GPS/Levelling Benchmarks Over the Hellenic Mainland. Survey Review, 42(318), 327-344.

Lemoine, F. G., Kenyon, S. C., Factor, J. K., Trimmer, R. G., Pavlis, N. K., Chinn, D. S., ... Torrence, M. H. (1998). The Development of the Joint NASA GSFC and the National Imagery and Mapping Agency (NIMA) geopotential model EGM96. Greenbelt, M.D. Retrieved from https://ntrs.nasa.gov/archive/nasa/casi.ntrs.nasa.gov/19980218814.pdf 
Łyszkowicz, A. (2009). Assessment of Accuracy of EGM08 Model Over the Area of Poland. Technical Sciences, 12, 118-134. http://doi.org/10.2478/v10022-009-0011-x

Moya, J., \& Dörries, E. (2016). Estudio de la ondulación del Geoide. Uniciencia, 21(1), 151-155.

National Imagery and Mapping Agency. (1997). Department of Defense World Geodetic System 1984: Its Definition and Relationship with Local Geodetic Systems. NIMA TR8350.2, 8350.

NOAA. (1981). National Geodetic Survey. Geodetic Levelling. Retrieved from http://www.ngs.noaa.gov/PUBS_LIB/ pub_ops.shtml

NOAA. (1995). National Geodetic Survey. FGCS Specifications and Procedures to Incorporate Electronic Digital/BarCode Leveling Systems. Retrieved from http://www.ngs.noaa.gov/PUBS_LIB/pub_ops.shtml

Pavlis, N. K., Holmes, S. A., Kenyon, S. C., \& Factor, J. K. (2012). The Development and Evaluation of the Earth Gravitational Model 2008 (EGM2008). Journal of Geophysical Research: Solid Earth, 117(B4). http://doi. org/10.1029/2011jb008916

Ries, J., Bettadpur, S., Eanes, R., Kang, Z., Ko, U., McCullough, C., ... Tapley, B. (2016). The Combined Gravity Model GGM05C. Potsdam. http://doi.org/http://doi.org/10.5880/icgem.2016.002

Seigle, H. O. (1995). A guide to high precision land gravimeter surveys. Ontario: Scintex Limited.

Sanchez, L. (2003). Determinación de la superficie vertical de referencia para Colombia. Degree Thesis. Dresden, Technische Universität Dresden, 106pp.

Sobrino, J. A. S., Mourón, A. D., \& Fernández, A. B. (2009). El nuevo modelo de Geoide para España EGM08-REDNAR. Topografía Y Cartografía: Revista Del Ilustre Colegio Oficial de Ingenieros Técnicos En Topografía, 26(155), 4-16.

Szúcs, E. (2012). Validation of GOCE Time-Wise Gravity Field Models Using GPS-Levelling, Gravity, Vertical Deflections and Gravity Gradient Measurements in Hungary. Periodica Polytechnica. Civil Engineering, 56(1), 3.

Torge, W., \& Müller, J. (2012). Geodesy. Walter de Gruyter.

Vaníček, P., Kingdon, R., \& Santos, M. (2012). Geoid versus quasigeoid: a case of physics versus geometry. Contributions to Geophysics and Geodesy, 42(1), 101-118.

Vaníček, P., Santos, M., Tenzer, R., \& Hernández-Navarro, A. (2003). Algunos aspectos sobre alturas ortométricas y normales. Revista Cartográfica, (76/77), 79. 